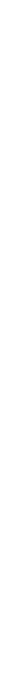

\title{
Varanasi - The Together Project
}

\author{
Authors: Johanna Patton \\ Submitted: $\quad$ 14. March 2021 \\ Published: $\quad$ 11. April 2021 \\ Volume: 8 \\ Issue: 2 \\ Affiliation: University, Freiburg and Johanna Patton Photography, Freiburg, \\ Germany \\ Languages: English \\ Keywords: $\quad$ Varanasi, India, Asia, Hinduism, Ganges River, Humanity, \\ Documentary Photography \\ Categories: Humanities, Social Sciences and Law \\ DOI: $\quad$ 10.17160/josha.8.2.744
}

\section{Abstract:}

The Together Project is a series of photo essays inspiring us to see humankind in a different light by honoring our cultural differences as well as the understanding that we're all cut from the same cloth; we're members of humankind. The Together Project is here to inspire you to learn about others and to ignite a sense of curiosity and compassion towards those who live in different cultures from our own. In this photo essay, Johanna explores Varanasi, India shares her experience as well as the customs that take place in the enchanting city. 


\title{
The Together Project: Varanasi, India
}

\author{
Johanna Patton
}

Keywords: Varanasi, India, Asia, Hinduism, Ganges River, Humanity, Documentary Photography

\section{Abstract}

The Together Project is a series of photo essays inspiring us to see humankind in a different light by honoring our cultural differences as well as the understanding that we're all cut from the same cloth; we're members of humankind. The Together Project is here to inspire you to learn about others and to ignite a sense of curiosity and compassion towards those who live in different cultures from our own.

In this photo essay, Johanna explores Varanasi, India shares her experience as well as the customs that take place in the enchanting city. 


\section{JOSHA}

Journal of Science, Humanities and Arts

\section{The Together Project}

\section{Varanasi, India}

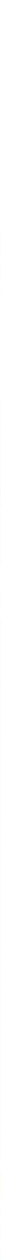




\section{The City of Shiva}

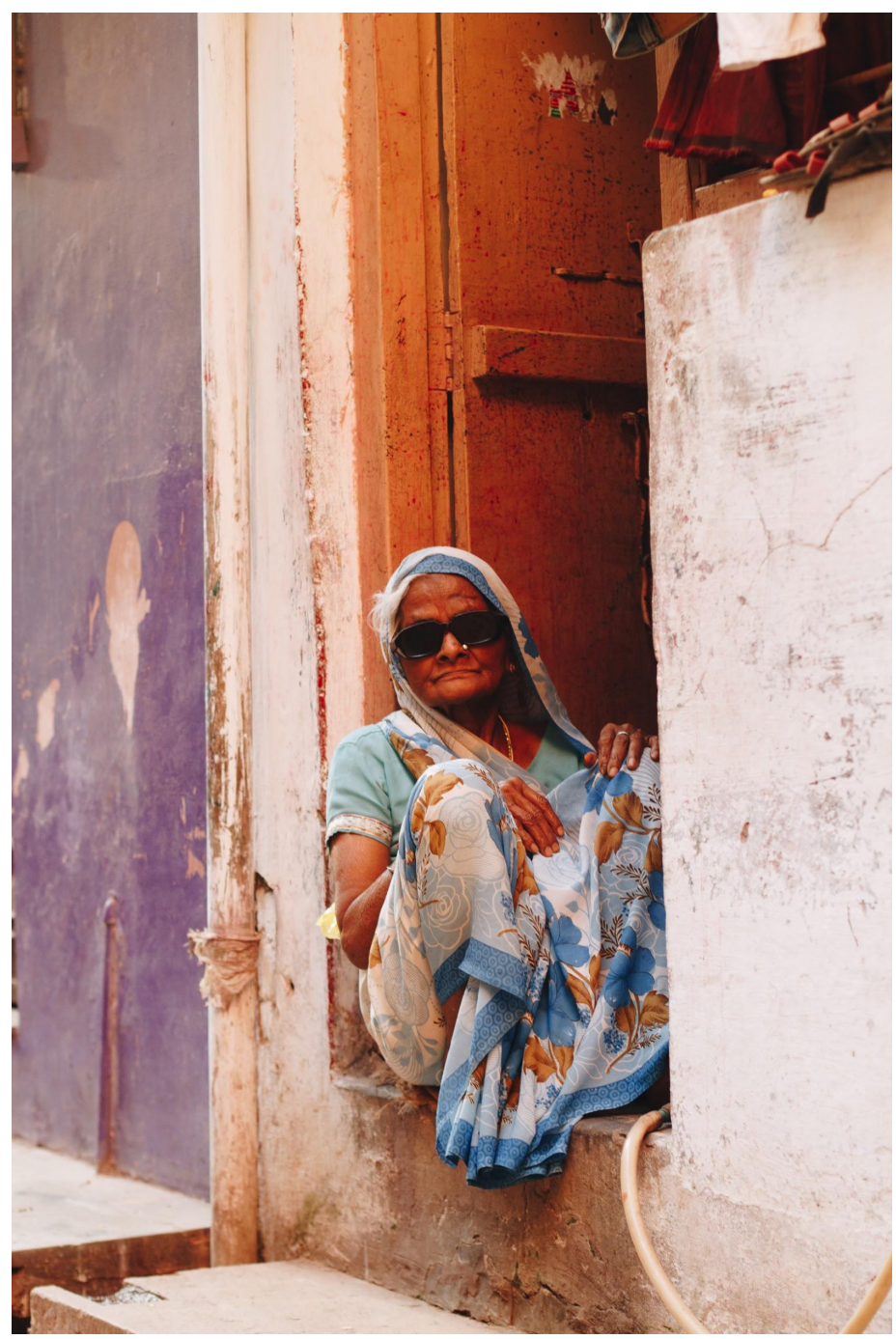

Varanasi is the city of Shiva and the home to the holy Ganga river. The energy of the city is something else. It sticks to me like honey as I tromp through dust-filled alleyways. The world feels a little bit more magical herebut also very heavy. It's colorful and chaotic and like nothing else l've ever felt or seen.

I am greeted by women poking their heads out of the doorways in bright colored sarees wearing red bhindis. A cow is having his afternoon nap in said alleyway, blocking 16 motorbikes, a rickshaw, a couple of taxis, and a tractor. This is a city that strikes every sense and heightens it by 20. There is a constant stream of honking horns that reaches every corner of the city complimented by the smell of burning bodies. The sound of chugging motorboats visitors through the ganga flows through the ghats. Sadhus (holy men) sit in the smoke of incense next to the river in their orange robes and dreaded hair, sipping on piping hot chai in small terracotta cups. Boat drivers sell their hour-long rides to the passersby. Groups of pilgrims fill this city from around the world. Celebrations and chaos are found with every corner you pass. 


\section{JOSHA}

Journal of Science, Humanities and Arts

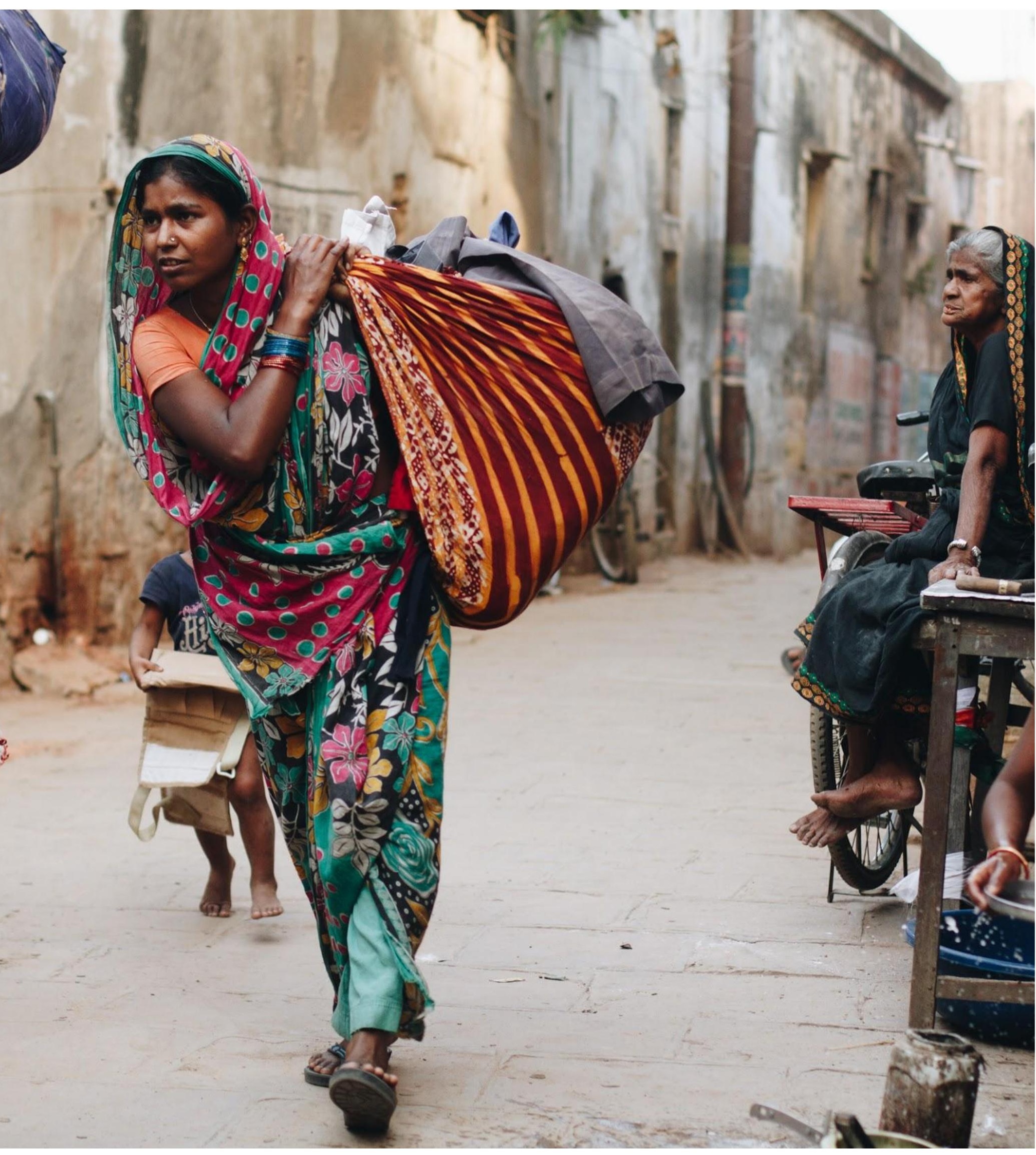




\section{JOSHA}

Journal of Science, Humanities and Arts

March 2021

Volume 8 , Issue 2

Hindu scriptures say that dying in Varanasi and being cremated next to the holy Ganga river can give you the most special gift of all- it ends the cycle of rebirth so you can finally attain salvation. That's the reason it is a goal for so many Hindus to come here at the end of their lives. By being burned in Varanasi, Hindu followers can end their karmic cycle. In a similar light, washing yourself with the water is not only seen as a means to purify oneself, but it is said that those who bathe in it will become a holy person and will have their bad karma diminished.

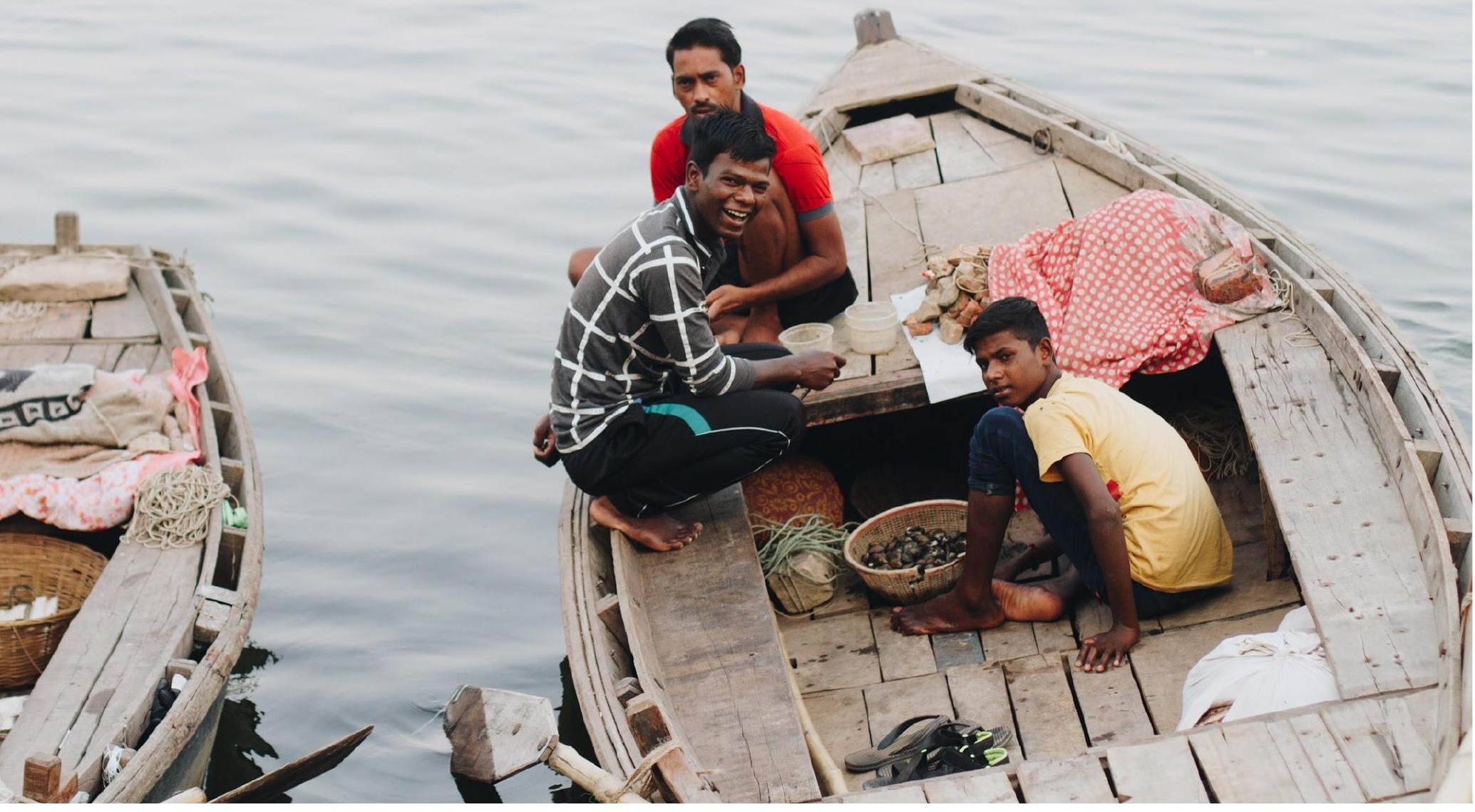




\section{JOSHA}

Journal of Science, Humanities and Arts
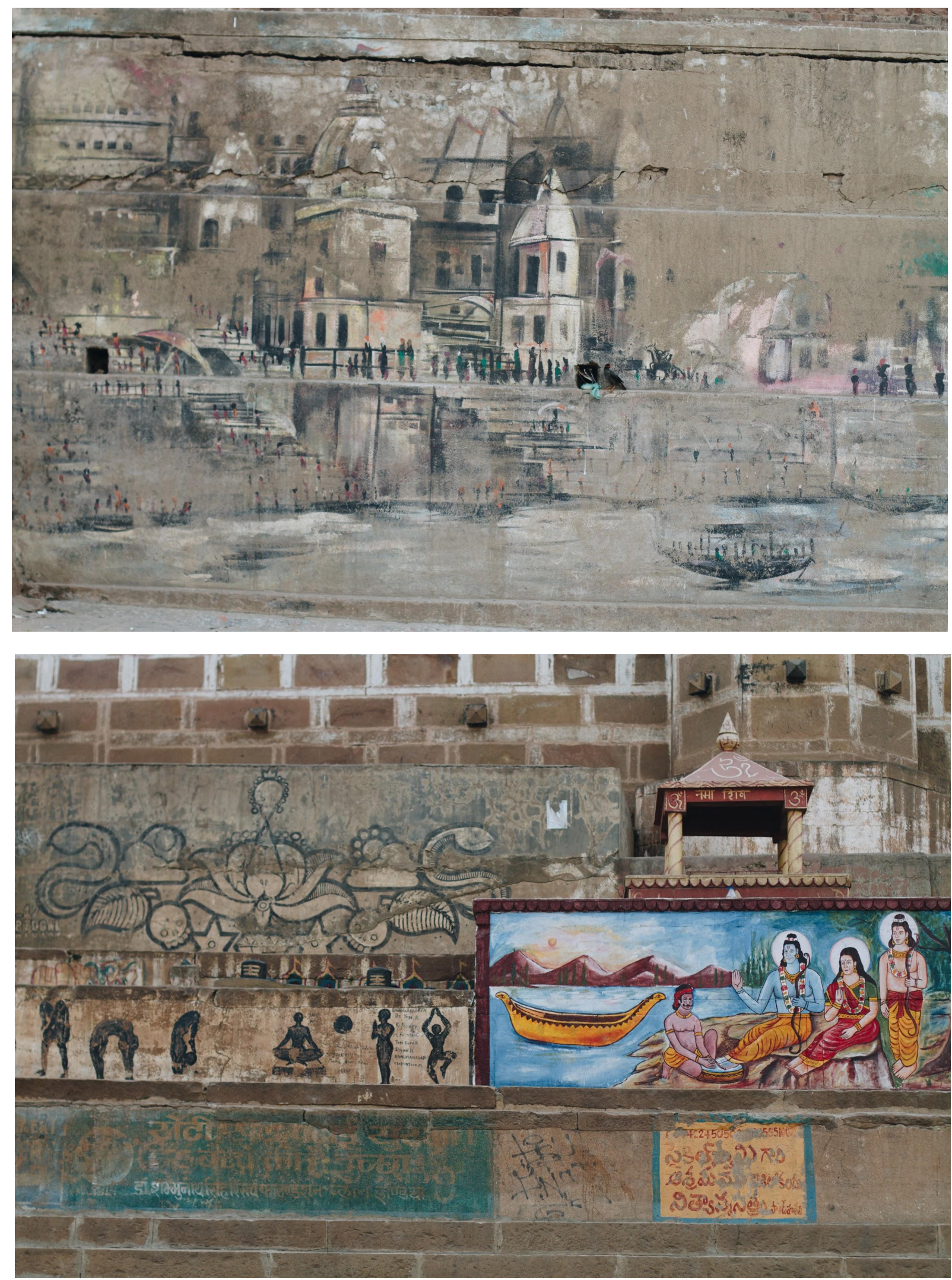


\section{JOSHA}

Journal of Science, Humanities and Arts

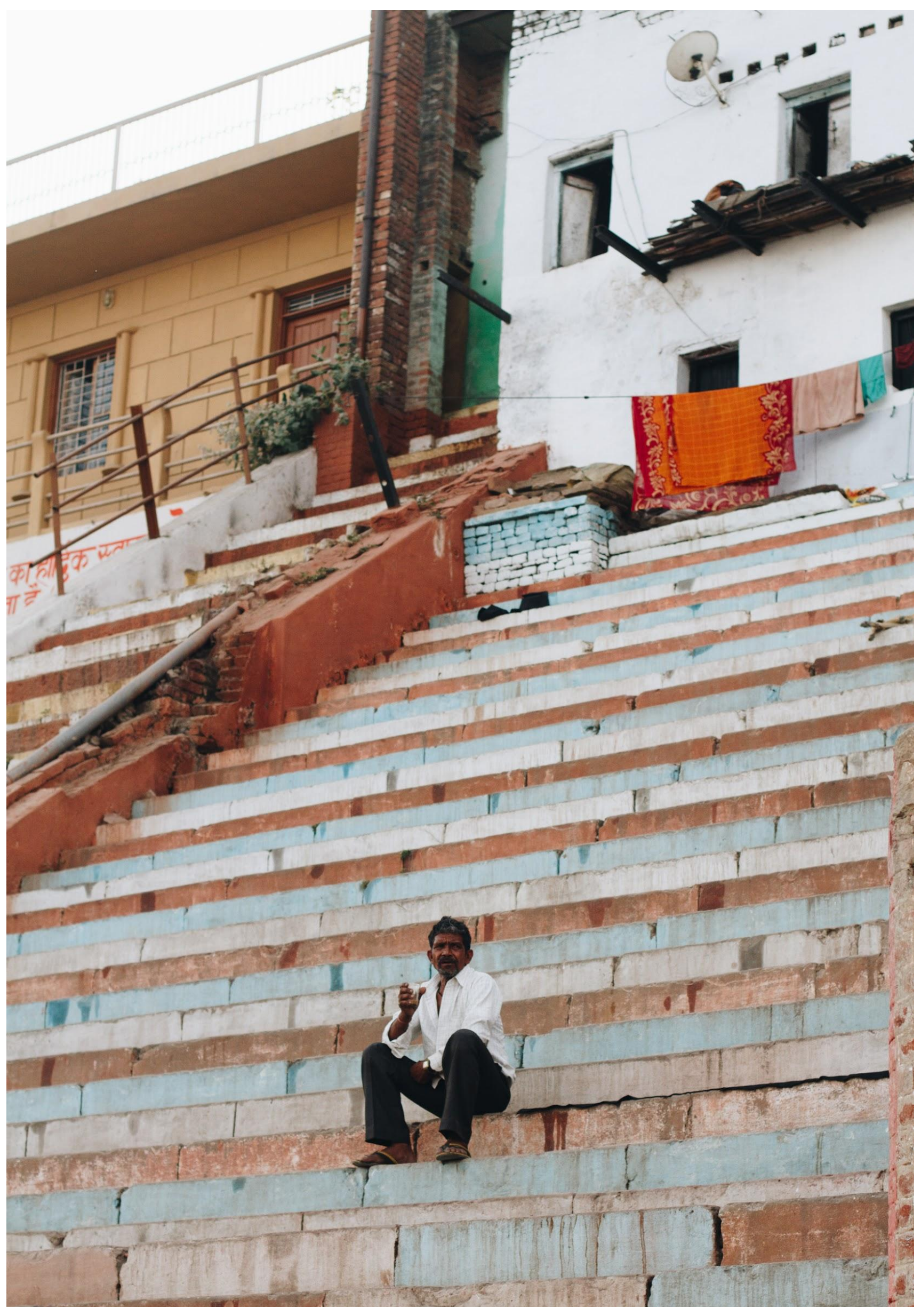


In fact, a friend told me a story of an Indian man she met when she was on the train to Varanasi. She had spent hours speaking to him about all things in the world during a long, rickety train ride. Finally the question arose after hours of chatting,

"Why are you going to Varanasi?" She asked,

Without flinching he responded, "I'm dying."

"You're dying?!"- shocked, of course not only at the absolute causality of the sentence but also at the fact that someone could possibly know when they were going to pass away. She proceeded to ask, "How do you know?"

"I just do. I have about three days left, I think. I have saved up my entire life to be burned in the city."

And it was the peace and acceptance the man on the train exemplified; that he acknowledged he was not only in this world to live, but also to die. It was the reason he was spending the last days of his life were spent traveling to the holy site. This conversation perfectly exemplifies the hard lessons I began to learn during my time in Varanasi.

I had never lived where death and life were so close together. In fact, I had always seen death and life to be two very opposites. Life must be light, and death must be darkness? But there is not one without the other, and things aren't just "good and bad" or "wrong or right" in the world. We can't have one without the other. 


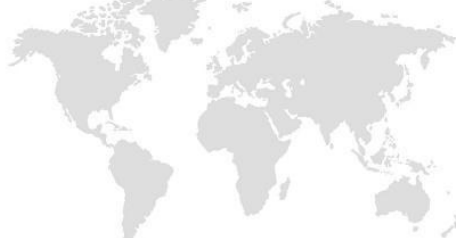

\section{JOSHA}

March 2021

Volume 8, Issue 2

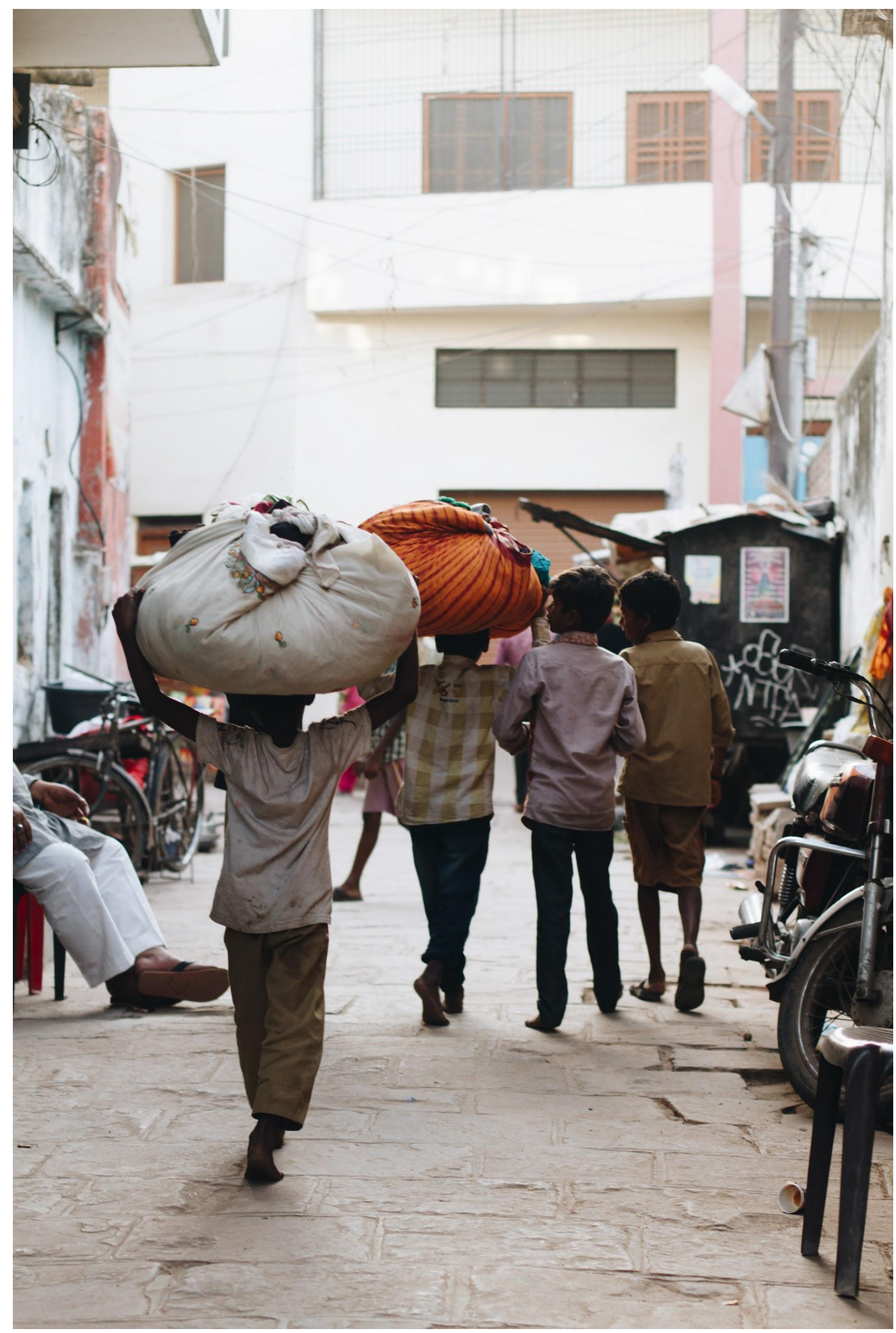




\section{JOSHA}

Journal of Science, Humanities and Arts
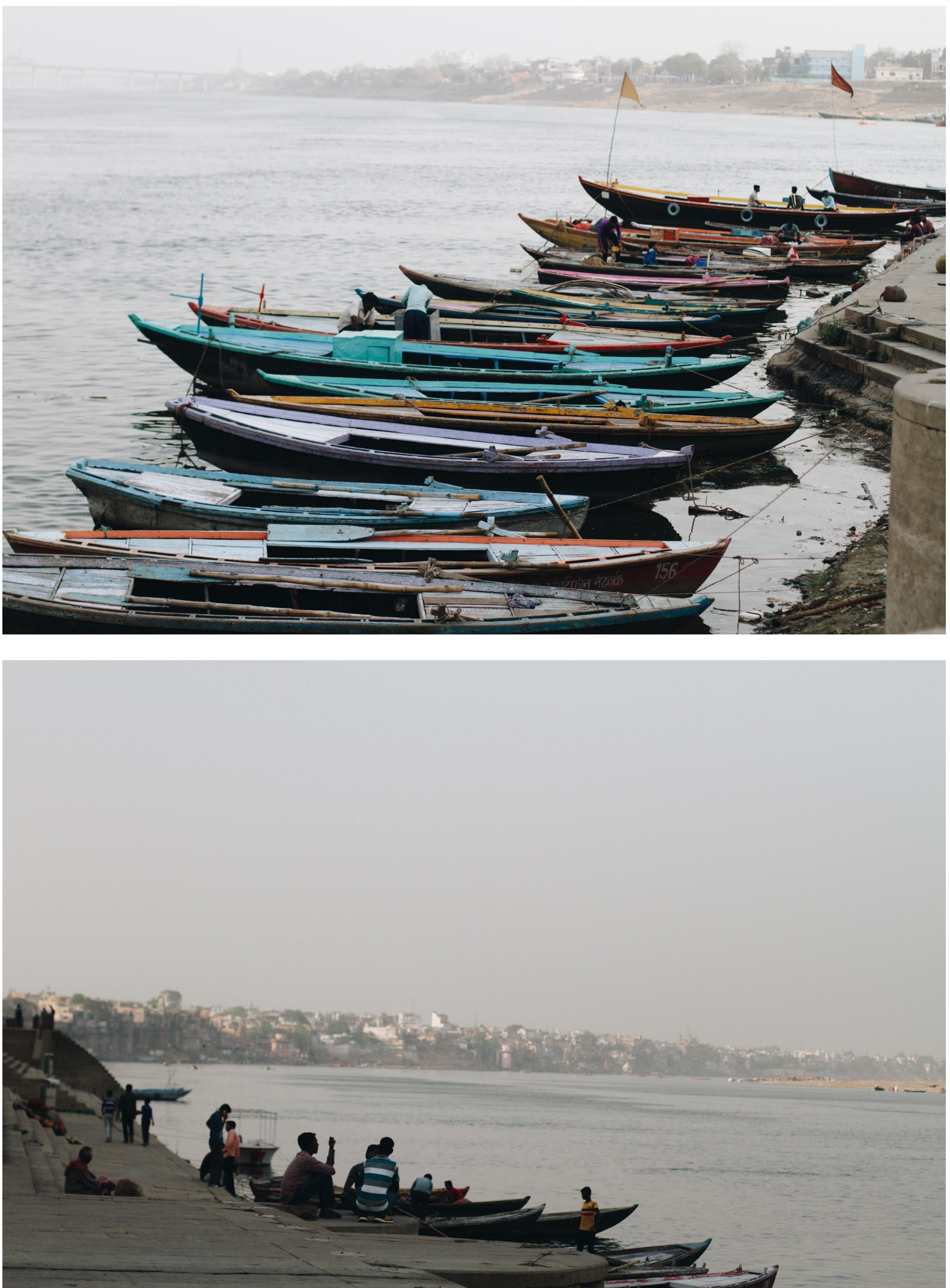


\section{JOSHA}

Journal of Science, Humanities and Arts

You see this being exemplified at all hours of the day at the Ganga (Ganges) river. There were days I would watch the cremation ceremony. Just next to it, I would watch children jumping, hooting, and hollering as they swam and did back-flips into the same water where the bodies were being released. Other followers used holy water to wash their laundry, while some were there to bathe themselves. There were other times when I would see large masses rising to the top of the river- bodies that had risen to the bottom of the water, making their way along with the current.

No matter what life journey you're on, this city will show you that life is so much more to think, feel, and understand about the world than what we see and experience on a daily basis. Varanasi, also called the "great grandfather of India" will push you, stretch you and shake you wide awake.

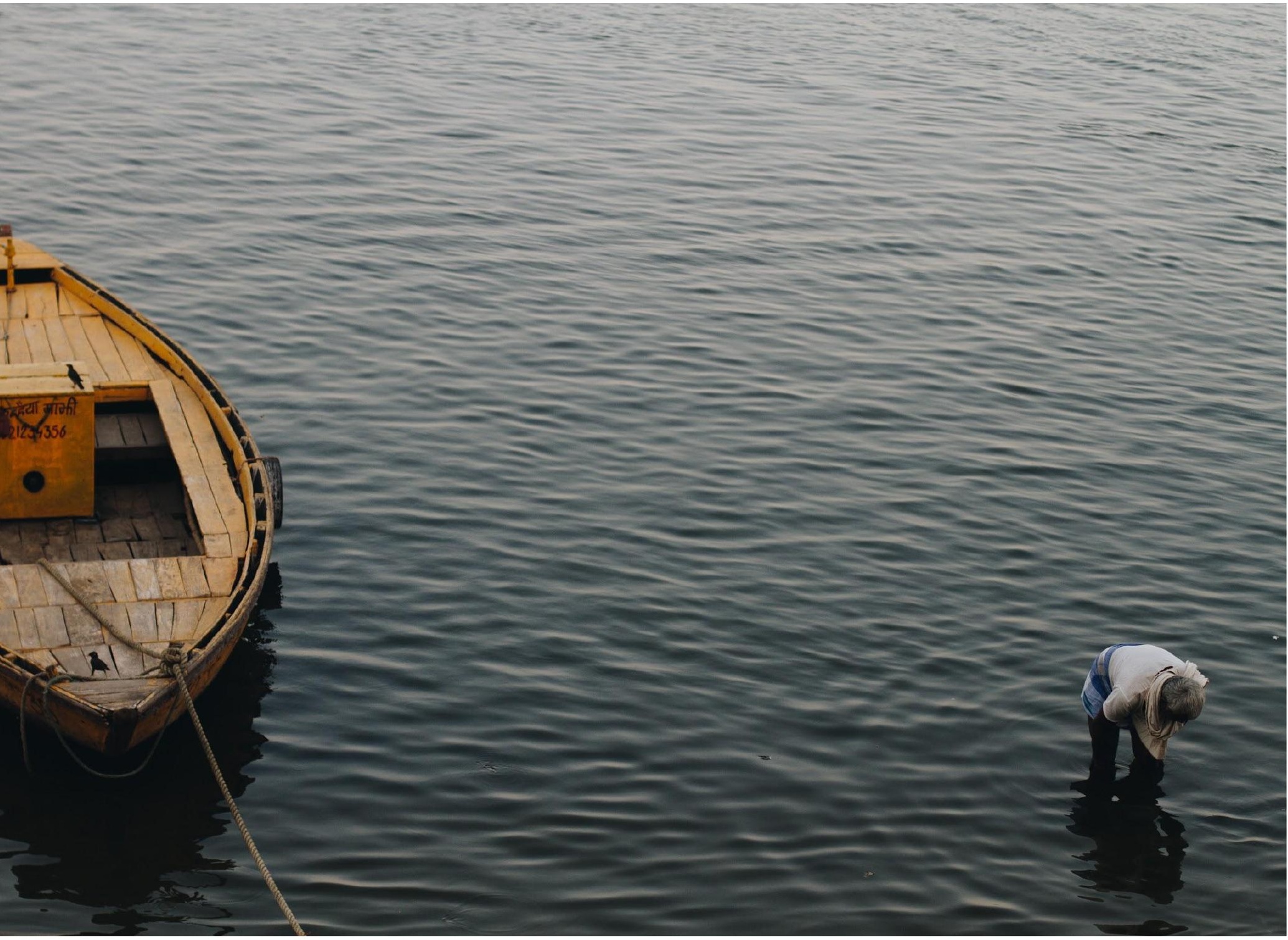




\section{JOSHA}

Journal of Science, Humanities and Arts

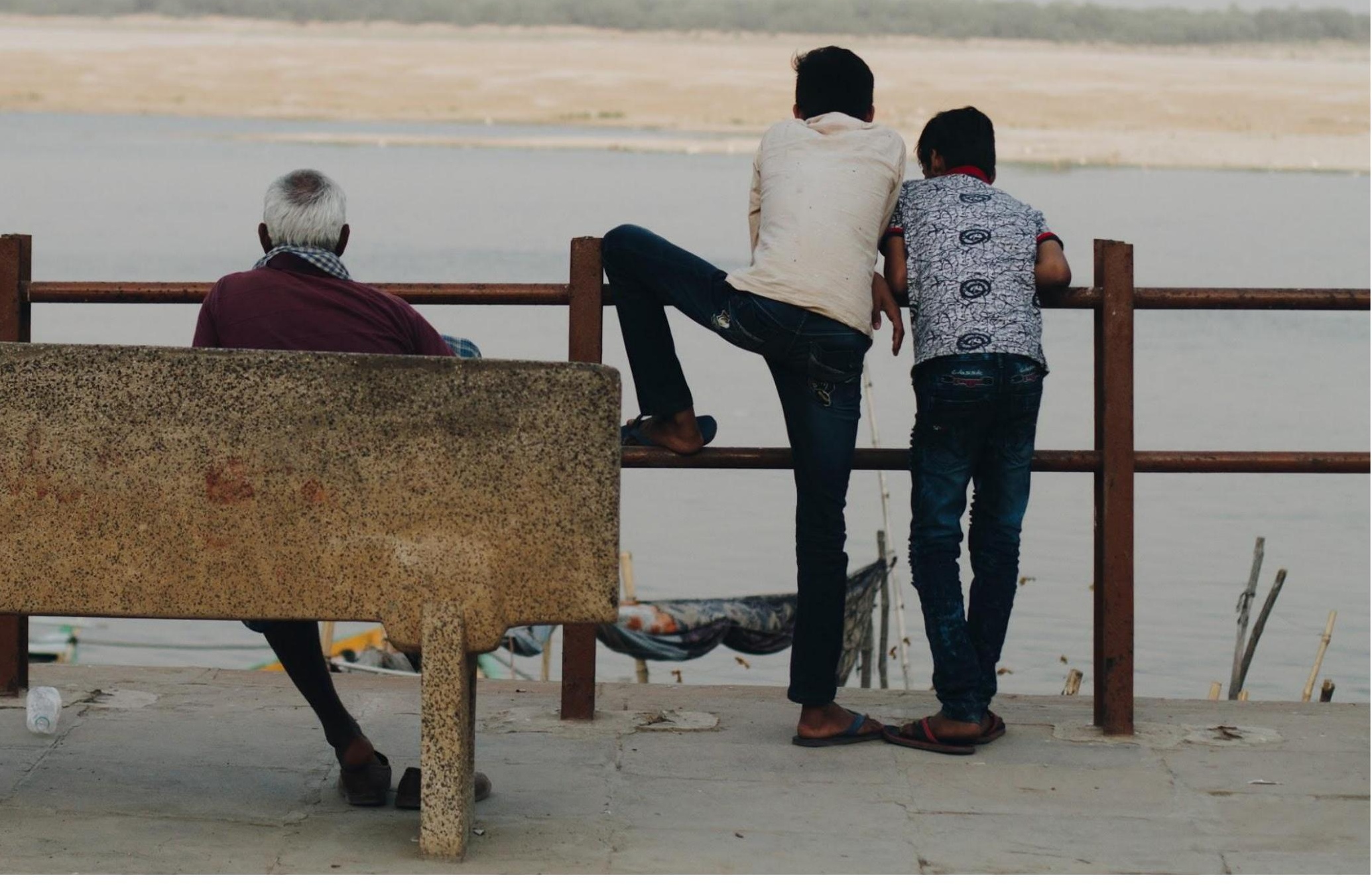




\section{JOSHA}

Journal of Science, Humanities and Arts

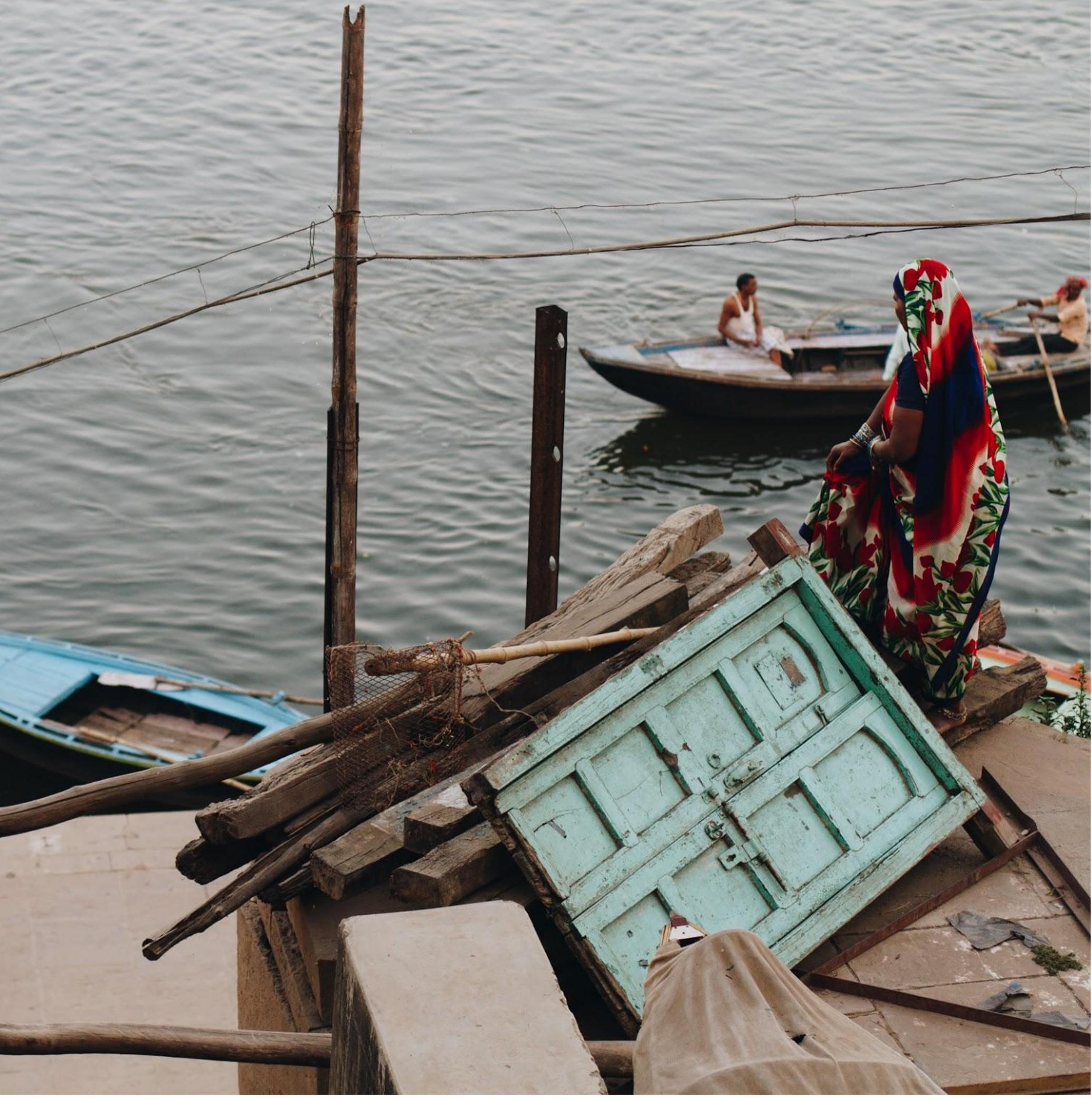




\section{JOSHA}

Journal of Science, Humanities and Arts
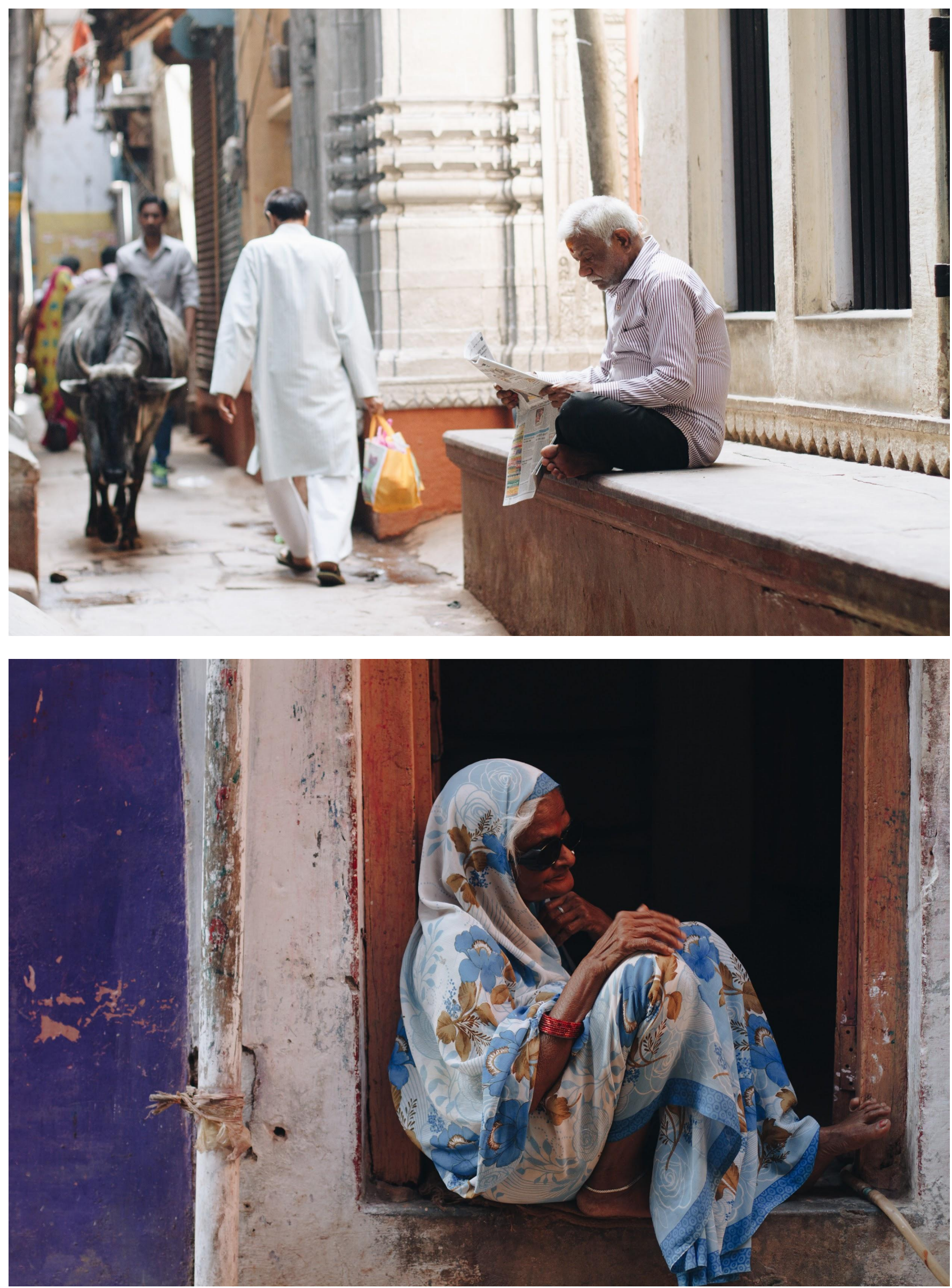


\section{JOSHA}

Journal of Science, Humanities and Arts

\section{About the Author:}

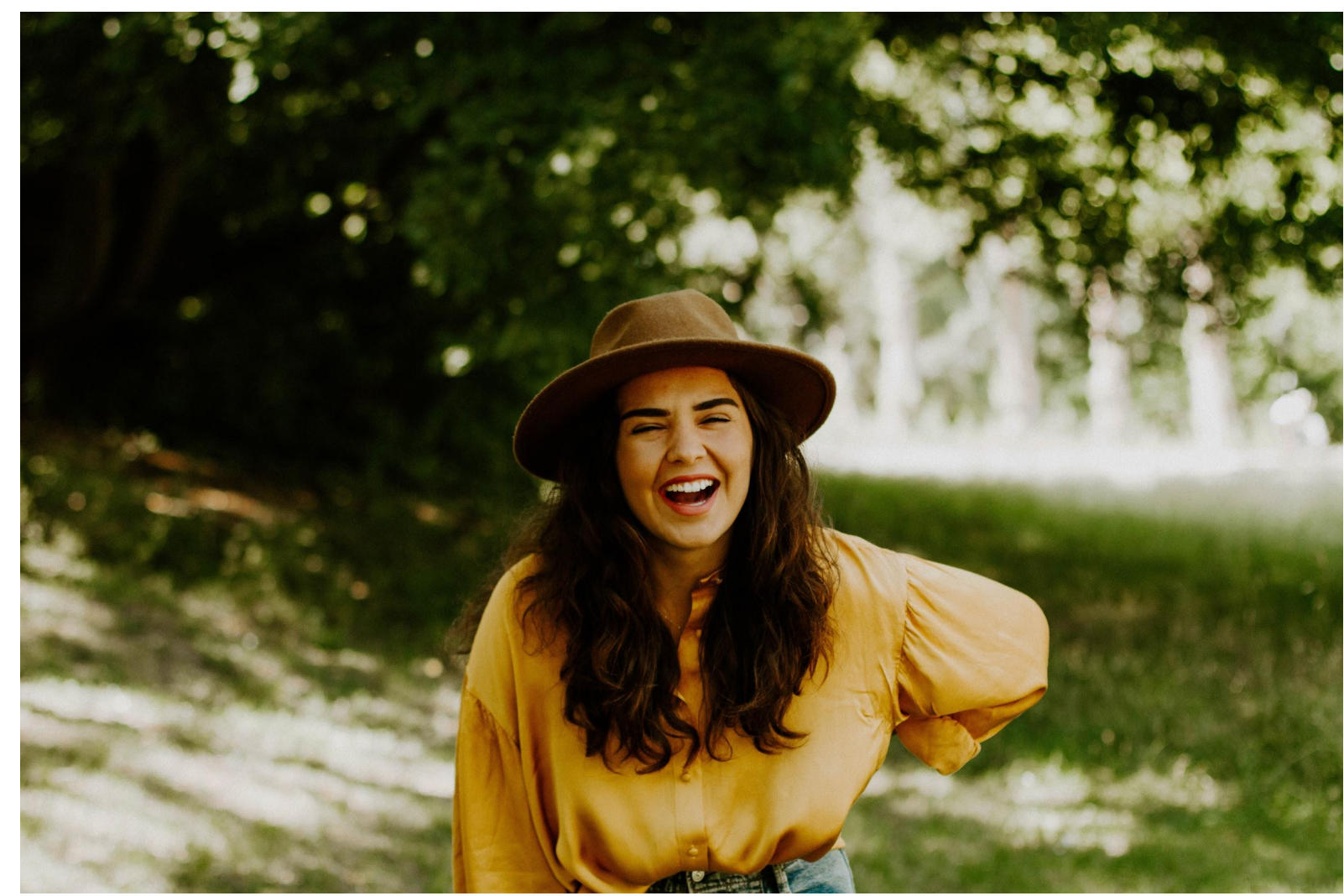

I'm Johanna, a Mexican-American portrait photographer, sometimes-writer, ethnology student, and the heart behind of The Together Project currently calling Freiburg, Germany home!

I'm passionate about sharing the kindness, light, and connection that humans have shown me across the globe- which is ultimately the inspiration behind The Together Project.

The Together Project is a series of photo essays inspiring us to see humankind with a sense of curiosity and compassion. The Together Project is here to inspire you to learn something new and meaningful about a culture you may have never known about, creating a sense of understanding and connection towards a people you may have not yet come into contact with.

If you'd like to see more of my work, feel welcome to visit my website at http://www.johannapatton.com 